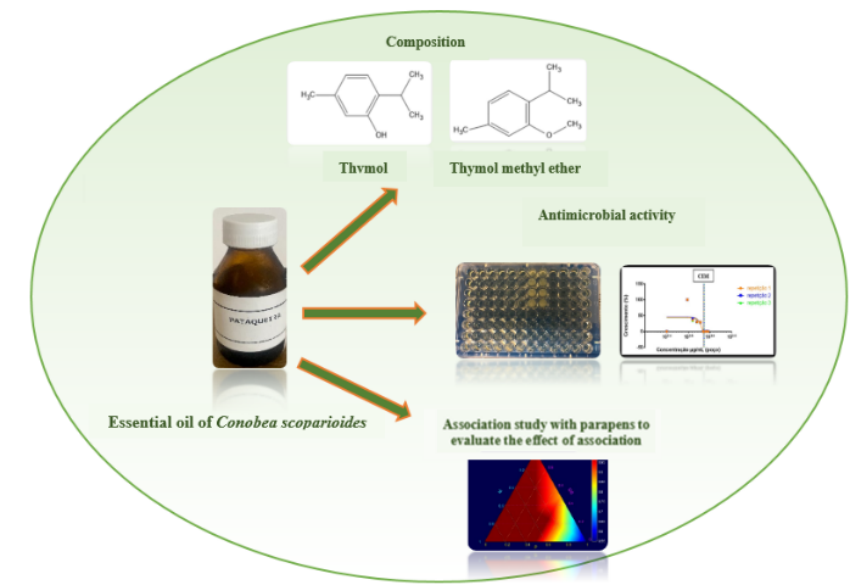

Antimicrobial activity of Conobea scoparioides essential oil, and its association with synthetic preservatives.

\title{
COMPOSIÇÃO QUÍMICA, ATIVIDADE ANTIMICROBIANA DE DO ÓLEO ESSENCIAL DE CONOBEA SCOPARIOIDES E SUA ASSOCIAÇÃO COM CONSERVANTES SINTÉTICOS \\ PARA UTILIZAÇÃO EM FORMULAÇÕES COSMÉTICAS
}

Cristina M. T. S. Miguel ${ }^{1}$, Cristina H. Serra ${ }^{1}$, Marcus T. Scotti ${ }^{2}$, Paulo R. H. Moreno ${ }^{1,3^{*}}$

1-Programa de Pós Graduação de Fármaco e Medicamentos - Universidade de São Paulo.

2. Departamento de Química, Centro de Ciências Exatas e da Natureza, UFPB, Campus I

3 -Instituto de Química, Universidade de São Paulo (USP), São Paulo, SP

prmoreno@iq.usp.br

Resumo: O presente trabalho visa avaliar a composição química do óleo essencial de Conobea scoparioides Cham. \& Schltdl., o seu potencial antimicrobiano e o efeito de sua associação com parabenos em bases cosméticas. Seus compostos majoritários são: éter metílico do timol (39,2\%), timol $(33,8 \%)$ e $\alpha$-felandreno $(15,9 \%)$. A atividade antimicrobiana do óleo essencial e do timol foi acessada através da concentração inibitória mínima (CIM), cujos resultados em $\mu \mathrm{g} / \mathrm{mL}$ para o óleo essencial e o timol foram respectivamente: S. aureus 650,7 e 284,9, E. coli 721,5 e 271,2, P. aeruginosa 1748,0 e > 2.000, B. cepacia 833,0 e 1.077,7, C. albicans 521,43 e 172,61 e A. brasiliensis 300,0 e 400. O efeito sinérgico da associação foi realizado através de um delineamento experimental centroide simplex para uma mistura de metilparabeno e propilparabeno e óleo essencial frente aos mesmos micro-organismos utilizados na determinação da atividade antimicrobiana. As concentrações obtidas em $\mu \mathrm{g} / \mathrm{mL}$ foram: 1120 para o metilparabeno, 350 para o propilparabeno e 675 para o óleo essencial. O óleo essencial de C. scoparioides apresentou um potencial antimicrobiano importante tanto sozinho como em associação com conservantes sintéticos. Estes resultados sugerem que esse óleo pode ser usado para compor um sistema conservante para formulações cosméticas contendo uma menor quantidade de sintéticos.

Palavras-chave: Conservantes. Óleos Essenciais.Conobea scoparioides. Atividade Antimicrobiana. Sinergia.

\section{Chemical composition, antimicrobial activity of Conobea scoparioides essential oil and its association with synthetic preservatives for use in cosmetic formulations}

Abstract: The present work aims to evaluate the chemical composition of the essential oil of Conobea scoparioides Cham. \& Schltdl., its antimicrobial potential, and the effect of its association with parabens in cosmetic bases. The major oil compounds were thymol methyl ether (39.2\%), thymol (33.8\%) and $\alpha$-phellandrene (15.9\%). The antimicrobial activity of essential oil and thymol was accessed through the minimum inhibitory concentration (MIC), whose results in $\mu \mathrm{g} / \mathrm{mL}$ for essential oil and thymol were respectively: S. aureus 650,7 and 284,9, E. coli 721,5 and 271,2, P. aeruginosa 1748,0 and $>2,000$, B. cepacia 833,0 and 1.077,7, C. albicans 521,4 and 172,6, and A. brasiliensis 300,0 and 400,0. The synergistic effect of the association was carried out through a centroid simplex experimental design for a mixture of methylparaben, propylparaben, and essential oil against the same microorganisms previously used. The ideal concentrations obtained in $\mu \mathrm{g} / \mathrm{mL}$ were: 1120 for methylparaben, 350 for propylparaben and 675 for essential oil. The essential oil of $C$. scoparioides showed an important antimicrobial potential both alone and in association with synthetic 
preservatives. These results suggest that this oil can be used to compose a preservative system for cosmetic formulations containing lower amounts of synthetic compounds.

Keywords: Preservatives. Essential Oils. Conobea scoparioides. Antimicrobian activity. Synergism

\section{Introdução}

Nas últimas décadas, tem-se observado um aumento na demanda do mercado cosmético mundial por produtos naturais. O consumidor atual, tem se tornado cada vez mais criterioso, optando por produtos cada vez mais próximos da sua origem ${ }^{1,3}$. Produtos cosméticos com componentes naturais apresentam grandes atrativos, por serem ecologicamente corretos, potencialmente mais saudáveis e voltados à responsabilidade social ${ }^{2}$. Diante desse quadro, a indústria cosmética, está em busca de produtos que contenham substâncias naturais em suas formulações com propriedades fitocosméticas e/ou ação conservante, em substituição aos compostos sintéticos ${ }^{3}$.

Os conservantes apresentam dupla função numa formulação, a primeira de proteção do produto e a segunda de proteção ao consumidor. Porém de forma geral, são os componentes da formulação cosmética que podem causar alergia e dermatite de contato. Sendo assim, vem se tornando crescente a preocupação em relação à toxicidade de conservantes sintéticos, o que demonstra o interesse pela busca de produtos naturais para minimizar os efeitos tóxicos causados pelos sintéticos.

Os óleos essenciais em formulações cosméticas, além de sua função como fragrância, têm demonstrado ação inibitória no crescimento de vários patógenos tanto Gram-positivos quanto negativos ${ }^{4}$. Diante desse cenário vários estudos têm demostrado a importância na utilização dos óleos essenciais no combate aos micro-organismos patogênicos devido a sua ação antibacteriana, antifúngica e antiviral como uma alternativa viável na preservação de produtos tanto na indústria farmacêutica, alimentícia e cosmética ${ }^{5}$.

Dentre os óleos essenciais podemos citar o óleo de Conobea scoparioides Cham. \& Schltdl, popularmente conhecida como pataqueira. Esta é uma espécie nativa do Brasil, mas não endêmica. Entre suas características mais marcantes, destacam-se os constituintes timol, éter metílico do timol e $\alpha$-felandreno, presentes em seu óleo essencial, os quais possuem odores agradáveis ${ }^{6}$ e são de interesse para o mercado brasileiro de perfumes e cosméticos ${ }^{7}$. Uma outra característica importante são as propriedades antimicrobianas destes componentes.

Assim, a proposta deste estudo é avaliar o potencial antimicrobiano e o efeito sinergético do óleo essencial de C. scoparioides com metil- e propilparabeno, um grupo de conservantes sintéticos.

\section{Experimental}

O óleo essencial de Conobea scoparioides Cham. \& Schltdl, utilizado foi uma amostra comercial obtida da International Flavors \& Fragrances (IFF) (Santana do Parnaíba, São Paulo), a qual é utilizada na indústria de cosmética.

Determinação dos perfis cromatográficos por cromatografia a gás acoplada à espectrometria de massas (CG/EM).

A identificação dos compostos foi realizada conforme o método anteriormente descrito ${ }^{8}$, através da comparação dos espectros de massas e índices de retenção calculados (determinados em relação aos tempos de retenção de uma série de $n$-alcanos) com os espectros de massa encontrados na literatura e na biblioteca instalada no equipamento (Adams, NIST/Willey).

Determinação da atividade antimicrobiana do óleo essencial e seus compostos majoritários. 
Neste trabalho foram utilizadas 6 cepas, 4 bacterianas e 2 fúngicas: E. coli (ATCC 8739), S.aureus (ATCC 6538), P. aeruginosa (ATCC 9027), B. cepacia (ATCC 25416) C. albicans (ATCC 10231) e A. brasiliensis (ATCC 16404). O ensaio da atividade antimicrobiana, foi baseado através da determinação da concentração inibitória mínima (CIM) e para este foi utilizado o método de microdiluição com técnicas assépticas, empregando microplacas de cultura de células de fundo chato estéreis, adaptando-se os volumes de inóculo, amostra e meio de cultura para $200 \mu \mathrm{L}^{9,10,11}$, já estabelecido no grupo ${ }^{12}$, cuja leitura foi realizada através do leitor de microplacas (LGC Biotecnologia $\left.{ }^{\circledR}\right)$. Para A. brasilensis o ensaio foi realizado através do método de microdiluição, porém a leitura da verificação da inibição foi feita visualmente, considerando presença ou ausência de crescimento.

Delineamento experimental para avaliar o efeito da associação do óleo essencial com parabenos. Para este experimento foi utilizado o planejamento experimental em rede simplex centroide com pontos adicionais de uma mistura de três componentes, composto por dez ensaios diferentes para determinação dos valores de todos os seus coeficientes representados na Tabela $1^{13}$. Para a realização do estudo das associações foi utilizado o método de microdiluição com técnicas assépticas, empregando microplacas de cultura de células de fundo chato estéreis, adaptando-se os volumes de inóculo, amostra e meio de cultura para $200 \mu \mathrm{L}^{9,10,11}$. Os resultados foram apresentados na forma de gráficos de superfície resposta e contorno. As variáveis selecionadas neste estudo foram as CIM's do metilparabeno e do propilparabeno pré-determinados ${ }^{14}$ juntamente com a do óleo essencial.

Tabela 1. Composições obtidas através do delineamento experimental de misturas

\section{Resultados e Discussão}

\begin{tabular}{|c|c|c|c|}
\hline Composiçdes & Metilparabeno & Propilparabeno & Óleo Essencial \\
\hline \multicolumn{4}{|c|}{ Proporçōes dos componentes nas composiçð̌es (\%) } \\
\hline 1 & 100 & 0 & 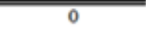 \\
\hline 2 & 0 & 100 & 0 \\
\hline 3 & 0 & 0 & 100 \\
\hline 4 & 50 & 50 & 0 \\
\hline 5 & 50 & 0 & 50 \\
\hline 6 & 0 & 50 & 30 \\
\hline 7 & 33 & 33 & 33 \\
\hline 8 & 50 & 25 & 25 \\
\hline 9 & 25 & 50 & 25 \\
\hline 10 & 25 & 25 & so \\
\hline
\end{tabular}

Após a análise de GC/MS, os principais componentes do óleo foram identificados como metil timol $(39,2 \%)$ e timol $(33,8 \%)$, a composição completa pode ser vista na Tabela 2.

Tabela 2. Composição química do óleo essencial das folhas de Conobea scoparioides.

\begin{tabular}{|c|c|c|c|c|c|c|c|}
\hline Composto & TR $^{2}$ & $\mathrm{LA}^{\mathrm{b}}$ & $\%$ & Composto & TR $^{\mathrm{a}}$ & $\mathbf{L A}^{\mathrm{b}}$ & $\%$ \\
\hline 3-octanona & 11,913 & 993 & 1,9 & timol metil éter & 23,638 & 1242 & 39,2 \\
\hline alfa-felandreno & 12,774 & 1012 & 15,9 & timol & 26,752 & 1311 & 33,8 \\
\hline p-cimeno & 13,635 & 1030 & 4,5 & alfa-trans-bergamoteno & 34,523 & 1493 & 1,3 \\
\hline 3-isopropenil-5,5-dimetil-ciclopenteno & 14,689 & 1052 & 0,5 & octacosano & 69,036 & 2673 & 1,3 \\
\hline N.I.5: $93(100 \%), 91(54 \%), 77(38 \%), 136(36 \%), 79(36 \%)$ & 15,034 & 1060 & 0,9 & Identificados & 99,1 & & \\
\hline linalol & 17,218 & 1106 & 0,7 & Não Identificados & 0,9 & & \\
\hline
\end{tabular}

a Tempo de retenção-coluna DB-5; b Índice de retenção-coluna DB-5; c Valores da literatura (ADAMS,2007; NIST); N.I.= não identificado.

Apesar das diferenças de composição química do óleo essencial de C. scoparioides encontradas na literatura, o timol sempre está entre os componentes majoritários. Assim, como vários estudos 
demostraram a ampla atividade antimicrobiana do timol ${ }^{15}$, podemos supor que esse óleo essencial poderá possuir um potencial antimicrobiano também.

As concentrações inibitórias mínimas do óleo essencial variaram de 200,0 a 1748,0 $\mu \mathrm{g} / \mathrm{mL}$. Quanto ao timol a variação ocorreu de 172,6 à $>2000 \mu \mathrm{g} / \mathrm{mL}$. Em relação às bactérias tanto para o óleo essencial quanto para o timol a mais resistente foi $P$. aeruginosa. Quanto aos fungos, A. brasiliensis, o bolor, foi mais sensível que a levedura $C$. albicans para o óleo essencial e mais resistente frente ao timol, conforme pode ser visto na figura 1.

Figura 1. Concentrações inibitórias mínimas determinadas para o óleo essencial de

C. scoparioides contra P. aeruginosa, B. cepacia, E coli, S. aureus, C. albicans $\mathrm{e}$

A. brasiliensis.

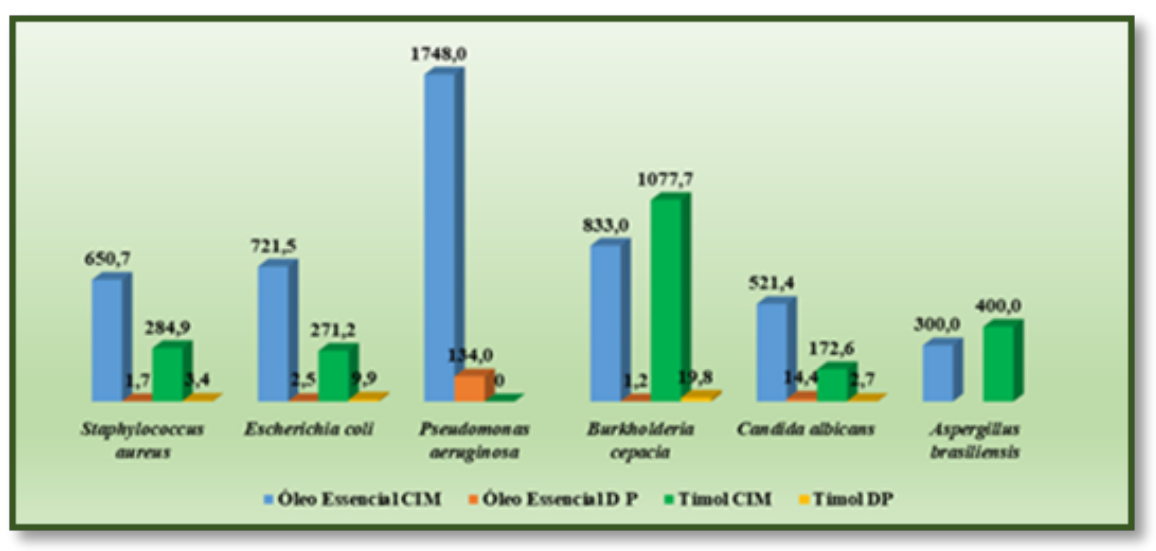

A ação antimicrobiana tanto do óleo essencial quanto do timol se deve provavelmente à natureza hidrofóbica dos dois compostos a qual interfere na integridade da membrana desse microorganismo. Um outro fator pode ser devido ao grupo hidroxila presente no timol que provoca o rompimento dos gradientes iônicos da célula bacteriana ${ }^{16}$. A concentração inibitória mínima muito elevada obtida para P. aeruginosa ocorreu, muito provavelmente, devido a sua capacidade de formação de biofilme, o que as tornam mil vezes mais resistentes aos agentes antimicrobianos do que quando encontradas em forma planctônica ${ }^{17}$. Um outro fator que leva a uma maior resistência de $P$. aeruginosa, que pode estar relacionado a membrana externa do gênero, por ser predominantemente impermeável aos compostos fenólicos do $\mathrm{OE}$, devido a existência de mecanismos de bombas de efluxo e inibição junto a porina que protegem a bactéria contra a ação de óleos essenciais ${ }^{18}$.

As associações realizadas com o óleo essencial e parabenos observou-se que houve inibição do crescimento microbiano de 95 a 100\% para bactérias tanto Gram positivas quanto Gram negativas. Para a levedura C. albicans, observou-se uma inibição de aproximadamente $78 \%$.

Através da análise estatística dos resultados das associações, foram calculadas as curvas contorno para a porcentagem de inibição $\mathrm{y}(\mathrm{x})$ das diferentes associações para cada micro-organismo em função das três variáveis $\left(\mathrm{X}_{1}, \mathrm{X}_{2}, \mathrm{X}_{3}\right)$ bem como sua representação em gráficos de calor. Estes resultados podem ser vistos na figura 2.

Com esses resultados podemos observar o efeito positivo da associação do óleo essencial com os parabenos, pois foi possível utilizar uma concentração abaixo da CIM de cada componente. Usando S. aureus como exemplo, isoladamente o metilparabeno apresenta um CIM $2000 \mu \mathrm{g} / \mathrm{mL}$, porém na associação podemos ter sua inibição com $400 \mu \mathrm{g} / \mathrm{mL}$, para o propilparabeno o valor obtido 
na associação foi de $250 \mu \mathrm{g} / \mathrm{mL}$ enquanto sua CIM é de $500 \mu \mathrm{g} / \mathrm{mL}$, já para o óleo essencial cuja a CIM é de $700 \mu \mathrm{g} / \mathrm{mL}$ a inibição foi observada a partir de $560 \mu \mathrm{g} / \mathrm{mL}$ na mistura.

\section{Conclusões}

O óleo essencial de C. scoparioides apresentou o timol como um dos principais compostos que já foi testado como agente antimicrobiano. O potencial antimicrobiano do óleo essencial determinado contra contaminantes cosméticos sozinho e associado aos parabenos, indicou que esse pode ser um promissor candidato para compor uma mistura conservante, contendo um ingrediente natural, em formulações cosméticas.

Figura 2. Curva de contorno (A) e gráfico de calor (B) das associações frente aos microorganismos $S$. aureus, P. aeruginosa, B. cepacia, E. coli, C. albicans e A. brasiliensis.

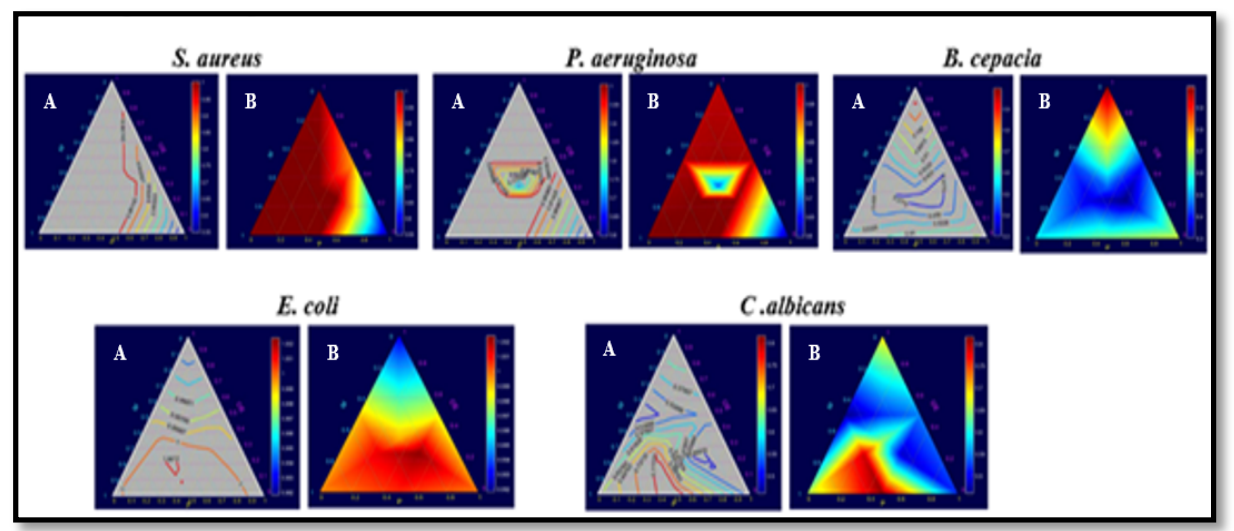

\section{Agradecimentos}

CAPES, International Flavors \& Fragrances (IFF) e Natura Cosméticos S/A.

\section{Referências}

1. Miguel, L. M. Revista Geográfica de América Central 2011, 1-15.

2. Flor, J. et al. Cosmetics \& Toiletries 2019, 30-36.

3. Packer; Luz, M. M. Brazilian Journal of Pharmacognosy 2007, 102-107.

4. Barakat, H. British Journal of Applied Science \& Technology 2014, 1934-1951.

5. Santos, F.S.; Novales, M. G. Current Opinion in Biotechnology 2012, 136-141.

6. Araújo, F.V. et al. Plantas da Amazônia para produção cosmética: uma abordagem química- 60 espécies do extrativismo florestal não-madeireiro da Amazônia 2007

7. Manual de Boas Práticas de Produção de Pataqueira, Natura Campus 2016.

8. Moreno, P. R. et al. The Journal of Essential Oil Research 2009,190-192.

9. NCCLS. Methods for Dilution Antimicrobial Susceptibility Tests for Bacteria That Grow Aerobically, Sixth Edition; 2003.

10. NCCLS. Method for Broth Dilution Tests to Determine the Antifungal Susceptibility of Filamentous Fungi; 2002.

11. NCCLS. Method for Broth Dilution Tests to Determine the Antifungal Susceptibility of Yeasts, Second Edition; 2002.

12. Moreno, P. R. et al. Current Topics in Medicinal Chemistry 2013, 3040-3078. 
13. Neto, B. D. et al. Pesquisa e Desenvolvimento na Ciência e na Indústria, 2010, 315-361.

14. Issa, F. Avaliação das atividades antioxidante e antimicrobiana de extratos de Apoclada simplex McClure \& Smith (Poaceae: Bambusoideae) 2015.

15. Wang, Y.; Yam, K. L. Food Packaging and Shelf Life 2018 92-96.

16. Sim, J. X. F. et al. Veterinary Dermatology 2019, 524-530.

17. Drenkard, E. Microbes and Infection 2003, 1213-1219.

18. Hossain, S. et al. Laboratory Animal Research 2017,195. 